\title{
Philosophiques
}

\section{Livres reçus (automne 2000)}

Volume 27, numéro 2, automne 2000

URI : https://id.erudit.org/iderudit/004948ar

DOI : https://doi.org/10.7202/004948ar

Aller au sommaire du numéro

Éditeur(s)

Société de philosophie du Québec

ISSN

0316-2923 (imprimé)

1492-1391 (numérique)

Découvrir la revue

Citer ce document

(2000). Livres reçus (automne 2000). Philosophiques, 27(2), 463-464.

https://doi.org/10.7202/004948ar

Ce document est protégé par la loi sur le droit d'auteur. L'utilisation des services d'Érudit (y compris la reproduction) est assujettie à sa politique d'utilisation que vous pouvez consulter en ligne.

https://apropos.erudit.org/fr/usagers/politique-dutilisation/
Cet article est diffusé et préservé par Érudit.

Érudit est un consortium interuniversitaire sans but lucratif composé de l’Université de Montréal, l'Université Laval et l'Université du Québec à Montréal. Il a pour mission la promotion et la valorisation de la recherche. https://www.erudit.org/fr/ 


\section{Livres reçus (automne 2000)}

Balat, Michel, Des Fondements sémiotiques de la psychanalyse. Peirce après Freud et Lacan. Suivi de la traduction de Logique des Mathématiques de C.S.Peirce. Paris, L'Harmattan (coll. «Ouverture philosophique »), 2000, 290 pages.

Barrette, Cyrille, Le miroir du monde. Évolution par sélection naturelle et mystère de la nature humaine. Sainte-Foy, MultiMondes, 2000, 354 pages.

Bollack, Jean, Jacob Bernays. Un homme entre deux mondes, Lille, Septentrion (coll. "Savoirs mieux, philologie », 2000, 120 pages.

Clair, André, Métaphysique et existence. Essai sur la philosophie de Jules Lequier. Paris, Vrin (coll. "Bibliothèque d'histoire de la philosophie »), 2000, 190 pages.

Cometti, Jean-Pierre, Jacques Morizot et Roger Pouivet, Questions d'esthétique. Paris, PUF (coll. "Premier cycle »), 2000, 221 pages.

Crépon, Marc, Le malin génie des langues (Nietzsche, Heidegger, Rosenzweig). Paris, Vrin (coll. " Problèmes et controverses »), 2000, 224 pages.

D’Alembert, Discours préliminaire de l'Encyclopédie. Introduit et annoté par Michel Malherbe. Paris, Vrin (coll. « Textes et commentaires »), 2000, 210 pages.

Engel, Pascal (dir.), Précis de philosophie analytique. Paris, PUF (coll. "Thémis »), 2000, 359 pages.

Michon, Pascal, Poétique d'une anti-anthropologie. L’herméneutique de Gadamer. Paris, Vrin (coll. "Problèmes et controverses »), 2000, 254 pages.

Milon, Alain, L'art de la conversation. Paris, PUF (coll. "Perspectives critiques »), 1999, 180 pages.

Mouraviev, Serge, Heraclitea. Édition critique complète des témoignages sur la vie et l'œuvre d'Héraclite d'Éphèse et des vestiges de son livre et de sa pensée. Sankt Augustin, Academia Verlag. 1. D’Épicharme à Philon d'Alexandrie, 1999, 270 pages. 2. De Sénèque à Diogène Laèrce, 2000, 402 pages.

Ratté, Michel, L'expressivité de l'oubli. Essai sur le sentiment et la forme dans la musique de la modernité. Bruxelles, La Lettre Volée (coll. «Essais »), 1999, 187 pages.

Spitz, Jean-Fabien, L'amour de l'égalité. Essai sur la critique de l'égalitarisme républicain en France (1770-1830). Paris, Vrin / EHESS (coll. "Contextes »), 2000, 286 pages. 


\section{Philosophiques / Automne 2000}

Stevens, Annick, L'ontologie d'Aristote. Au carrefour du logique et du réel. Paris, Vrin (coll. «Bibliothèque d'histoire de la philosophie»), 2000, 301 pages.

Theau, Jean, De l'homme comme être moral, Paris, Pierre Téqui (coll. "Croire et savoir »), 1999, 446 pages.

Outre les ouvrages qui apparaissent dans cette liste, la rédaction de Philosophiques peut obtenir, pour fin de compte-rendu, la plupart des livres publiés récemment aux Presses Universitaires de France, chez Vrin, au Seuil et à L'Harmattan.

Les personnes désireuses de faire un compte-rendu sont priées de s'adresser à :

Daniel Dumouchel Université de Montréal

Département de philosophie C.P. 6128 Succ. Centre-ville Montréal, Québec, H3C 3J7

Tél : (514) 343-6484

Télec : (514) 343-7899

Courriel : dumouchd@netcourrier.com 